\title{
Characteristics and outcomes of patients with percutaneous coronary intervention for unprotected left main coronary artery disease: a Hong Kong experience
}

\author{
KY Lo *, CK Chan
}

\section{A B S T R A C T}

Objective: To evaluate the intermediate-term outcomes of patients with unprotected left main coronary artery stenosis who were treated with percutaneous coronary intervention in Hong Kong.

Design: Historical cohort.

Setting: A regional hospital in Hong Kong.

Patients: Patients with unprotected left main coronary artery disease undergoing stenting with bare-metal stents or drug-eluting stents between January 2008 and September 2011.

Main outcome measures: Incidence of restenosis and major adverse cardiac and cerebrovascular events including cardiac death, non-fatal myocardial infarction, stroke, and target lesion revascularisation.

Results: Of the 111 patients included in the study, 86 received drug-eluting stents and 25 received baremetal stents. Procedural success was achieved in $98.2 \%$ of cases. Angiographic follow-up was available in $83.8 \%$ of cases and restenosis rate was significantly lower with drug-eluting stents than with bare-metal stents $(14.0 \%$ vs $40.0 \% ; \mathrm{P}=0.004)$. After a mean clinical follow-up of 26.1 (standard deviation, 12.6) months, the incidences of cardiac death $(5.8 \%$ vs $16.0 \% ; \mathrm{P}=0.191)$ and non-fatal myocardial infarction the risks of target lesion revascularisation (9.3\% vs $32.0 \% ; \mathrm{P}=0.001)$ and major adverse cardiac and cerebrovascular events $(19.8 \%$ vs $44.0 \%$; $\mathrm{P}=0.004)$ were significantly lower with drug-eluting stents than with bare-metal stents.

Conclusions: Performing percutaneous coronary intervention for unprotected left main coronary artery disease was safe and feasible in selected patients with high procedural success rate. The incidence of major adverse cardiac and cerebrovascular events in patients receiving drugeluting stents remains low after intermediate-term follow-up. Compared with bare-metal stents, drugeluting stents were associated with a lower need for repeating revascularisation without increasing the risk of death or myocardial infarction in patients with unprotected left main coronary artery disease.

\section{Hong Kong Med J 2014;20:187-93}

DOI: 10.12809/hkmj134069

KY Lo *, FHKCP, FHKAM (Medicine)

CK Chan, FRCP (Edin, Glasg), FHKAM (Medicine)

Division of Cardiology, Department of Medicine and Geriatrics, United Christian Hospital, Kwun Tong, Hong Kong eluting stents and bare-metal stents. However, * Corresponding author: lky972@ha.org.hk

New knowledge added by this study

- This study demonstrated that performing percutaneous coronary intervention (PCI) for unprotected left main coronary artery (ULMCA) disease in this Chinese cohort was safe and feasible in selected patients with high procedural success and good intermediate-term outcomes.

- The incidence of major adverse cardiac and cerebrovascular events in patients receiving drug-eluting stents (DES) in this cohort of patients was similar to that in other major clinical trials.

Implications for clinical practice or policy

- DES was associated with a lower need for repeating revascularisation without increasing the risk of death or myocardial infarction in patients with ULMCA disease than with bare-metal stents (BMS). Our results suggested that BMS should not be encouraged due to the high incidence of restenosis and target lesion revascularisation.

- PCI in ULMCA disease can be safely performed in a centre without on-site surgical support.

\section{Introduction}

Significant unprotected left main coronary artery (ULMCA) disease occurs in $5 \%$ to $7 \%$ of patients undergoing coronary angiography. ${ }^{1}$ Coronary artery bypass graft (CABG) surgery has been the standard of care for the treatment of ULMCA disease, and percutaneous coronary intervention $(\mathrm{PCI})$ is reserved for patients who are poor surgical 


\section{以香港的經驗來探討冠狀動脈介入治療術應用於 無保護左主冠狀動脈疾病患者的特徵和成果 \\ 盧家業、陳志堅}

目的：探討冠狀動脈介入治療術（PCI）應用於無保護左主冠狀動脈 疾病 (ULMCA) 患者的中期結果。

設計：歷史性隊列研究。

安排：香港一所分區醫院。

患者：曾於 2008 年 1 月至 2011 年9月期間接受置入裸金屬支架 (BMS) 或滲藥支架 (DES) 的ULMCA患者。

主要結果測量：血管再狹窄和主要不良心藏及腦血管事件, 包括心臟 性猝死、非致命性心肌梗塞、中風和病灶再重建的發生率。

結果：參與研究的 111 名患者中, 86 人接受了DES, 25 人接受了 BMS。手術成功率為 $98.2 \%$ 。血管造影跟進率為 $83.8 \%$, DES的血 管再狹窄率顯著較BMS低（ $14.0 \%$ 比 $40.0 \% ; \mathrm{P}=0.004)$ 。在平均 26.1（標準差12.6）個月的臨床跟進後, 使用DES或BMS的心藏性 猝死 $(5.8 \%$ 比 $16.0 \% ; \mathrm{P}=0.191)$ 或非致命性心肌梗塞 $(3.5 \%$ 比 $8.0 \% ; \mathrm{P}=0.262)$ 的發生率相近。然而, 使用DES比BMS的病灶再重 建 $(9.3 \%$ 比 $32.0 \% ； \mathrm{P}=0.001)$ 和主要不良心藏及腦血管事件 $(19.8 \%$ 比 $44.0 \% ; \mathrm{P}=0.004)$ 的風險均顯著下降。

結論：在選擇性ULMCA患者中進行PCI是安全和可行的, 手術成功 率亦非常高。患者在接受DES後的中期跟進中, 主要不良心臟及腦血 管事件發生率仍然偏低。ULMCA患者中, 在不增加死亡或心肌梗塞 的前提下, 與BMS相比, DES更能降低目標血管再重建的風險。

candidates. ${ }^{2}$ Recently, the use of drug-eluting stents (DES), together with advance in PCI technology, has improved the outcomes of patients undergoing PCI for ULMCA disease. The latest guidelines assign ULMCA PCI a class IIa indication which may be considered in patients who are at low risk for procedural complications and at increased risk of adverse surgical outcomes. ${ }^{3}$

Because of the risk of restenosis, it is not encouraged to use bare-metal stents (BMS) in ULMCA disease. The situation in Hong Kong is special in this regard. The public health care system (The Samaritan Fund) of Hong Kong does not cover the cost of using DES in ULMCA disease. Hence, patients with financial difficulty and who refuse to receive CABG can only undergo PCI with BMS implantation. Moreover, like other Asian countries, patients in Hong Kong are reluctant to have CABG, leaving them with the option of using BMS or medical treatment only. Because of this restraint, the proportion of patients with ULMCA disease in Hong Kong who are treated with BMS probably exceeds that in other developed countries.

The present study aimed to evaluate the outcomes of patients with ULMCA stenosis who were treated with PCI in Hong Kong.

\section{Methods}

\section{Study population}

This was a single-centre retrospective study performed to determine the outcomes of patients who had undergone ULMCA PCI. Between January 2008 and September 2011, 111 patients with ULMCA disease (defined as $>50 \%$ stenosis) received PCI with either DES or BMS implantation in the United Christian Hospital, Hong Kong. The cohort included unselected consecutive patients who presented with stable angina, acute coronary syndrome, or cardiogenic shock. Therefore, PCI could be performed in an elective or emergency setting (ie an all-comers basis). Moreover, there was no on-site surgical support in our centre.

The decision of performing PCI instead of CABG surgery was based on coronary anatomy, haemodynamic conditions, surgical risks, and patients' preference. Both interventional cardiologists and cardiac surgeons were involved in making the decision.

Unprotected left main coronary artery PCI was performed using standard techniques. Heparin 70 to 100 units per $\mathrm{kg}$ was administered before PCI. Intraaortic balloon pump counterpulsation, intravascular ultrasound (IVUS) or glycoprotein IIb/IIIa inhibitors was used at the discretion of the operators. All patients were pre-treated with 80 to $160 \mathrm{mg}$ aspirin and a loading dose of 300 to $600 \mathrm{mg}$ clopidogrel or $75 \mathrm{mg}$ maintenance dose of clopidogrel at least 7 days before the procedure. After PCI, aspirin 80 to $160 \mathrm{mg}$ daily and clopidogrel $75 \mathrm{mg}$ daily, for 1 month after BMS and 1 year after DES implantation, were prescribed. For ostial and shaft left main stenosis, single stent placement was preferred. Patients with bifurcation stenosis underwent one of the four types of bifurcation stenting techniques (T-stenting, $\mathrm{T}$ stenting and small protrusion technique, Culotte technique, or Crush technique) at the operators' discretion. Routine surveillance angiography was arranged for all patients 6 to 9 months after the index procedure, except in patients who refused, or with high risk for coronary angiogram. Baseline demographic, procedural, angiographic, and clinical outcome data were collected.

\section{Definitions}

Unprotected left main coronary artery stenosis was defined as $>50 \%$ stenosis without any patent graft to the left anterior descending artery or left circumflex artery. Procedure was defined as successful if revascularisation was achieved in the target lesion with $<30 \%$ residual stenosis in angiography and patient was discharged from hospital without any of these events: death, Q-wave myocardial infarction (MI), stroke, and target lesion revascularisation (TLR). 
TABLE I. Baseline clinical characteristics

\begin{tabular}{|c|c|c|c|c|}
\hline \multirow[t]{2}{*}{ Clinical characteristic } & \multicolumn{3}{|c|}{ Mean \pm standard deviation or No. (\%) of patients } & \multirow[t]{2}{*}{$P$ value } \\
\hline & All patients $(n=111)$ & DES ( $n=86)$ & BMS ( $n=25)$ & \\
\hline Age (years) & $68.4 \pm 10.3$ & $68.1 \pm 10.4$ & $69.6 \pm 9.9$ & 0.468 \\
\hline Male & $82(73.9)$ & $63(73.3)$ & $19(76.0)$ & 0.076 \\
\hline Diabetes mellitus & $61(55.0)$ & $46(53.5)$ & $15(60.0)$ & 0.332 \\
\hline Hypertension & $91(82.0)$ & $70(81.4)$ & $21(84.0)$ & 0.089 \\
\hline Current / ex-smoker & $57(51.4)$ & $41(47.7)$ & $16(64.0)$ & 0.198 \\
\hline Prior $\mathrm{PCl}$ & $28(25.2)$ & $24(27.9)$ & $4(16.0)$ & 0.228 \\
\hline Prior CABG & $3(2.7)$ & $1(1.2)$ & $2(8.0)$ & 0.127 \\
\hline Peripheral vascular disease & $4(3.6)$ & $2(2.3)$ & $2(8.0)$ & 0.218 \\
\hline Prior stroke & $12(10.8)$ & $7(8.1)$ & $5(20.0)$ & 0.093 \\
\hline Hypercholesterolemia & $88(79.3)$ & 67 (77.9) & $21(84.0)$ & 0.547 \\
\hline Chronic renal failure & $8(7.2)$ & $4(4.7)$ & $4(16.0)$ & 0.075 \\
\hline Left ventricular ejection fraction & & & & 0.164 \\
\hline$<35 \%$ & $6(5.4)$ & $4(4.7)$ & $2(8.0)$ & \\
\hline $35-55 \%$ & $38(34.2)$ & $26(30.2)$ & $12(48.0)$ & \\
\hline$>55 \%$ & $67(60.4)$ & $56(65.1)$ & $11(44.0)$ & \\
\hline Clinical indication & & & & 0.021 \\
\hline Stable angina & $49(44.1)$ & $43(50.0)$ & $6(24.0)$ & \\
\hline Acute coronary syndrome & $62(55.9)$ & $43(50.0)$ & $19(76.0)$ & \\
\hline
\end{tabular}

Abbreviations: $\mathrm{BMS}=$ bare-metal stents; $\mathrm{CABG}=$ coronary artery bypass surgery; $\mathrm{DES}=$ drug-eluting stents; $\mathrm{PCl}=$ percutaneous coronary intervention

Follow-up was completed in June 2012. Endpoints were restenosis and major adverse cardiac and cerebrovascular events (MACCE) including cardiac death, non-fatal MI, stroke, and TLR.

Restenosis was defined as $>50 \%$ luminal narrowing at the left main segment (stent and $5 \mathrm{~mm}$ proximal and distal) which was demonstrated at the follow-up angiography, regardless of patient symptoms.

Death was classified as cardiac or non-cardiac. Deaths that could not be classified were considered cardiac. Cardiac death was defined as death from any cardiac cause (eg MI, heart failure, or arrhythmia) or sudden unexplained death without an explanation. Non-Q-wave MI was defined as elevation of total creatine kinase 2 times above the upper normal limit in the absence of pathological Q wave. Target lesion revascularisation was defined as any revascularisation performed on the treated left main segment. Chronic kidney disease was documented if the serum creatinine level was $>200 \mu \mathrm{mol} / \mathrm{L}$ or was put on renal replacement therapy. Stent thrombosis was defined as definite and probable according to the Academic Research Consortium. ${ }^{4}$

\section{Statistical analyses}

Categorical variables reported as percentages and comparisons between groups were based on the Chi squared test or Fisher's exact test. Continuous variables were reported as mean \pm standard deviation, and differences were assessed with the independent sample $t$ test or Mann-Whitney test.

Cumulative event curves were calculated by the Kaplan-Meier method and compared by the log-rank test. A P value of $<0.05$ was considered statistically significant. Statistical analyses were performed with the use of the Statistical Package for the Social Sciences (Windows version 15.0; SPSS Inc, Chicago [IL], US).

\section{Results}

\section{Patient characteristics}

Baseline clinical, and angiographic and procedural characteristics of the 111 patients are summarised in Table 1 and Table 2, respectively.

Overall, $86(77.5 \%)$ patients were treated with DES, and $25(22.5 \%)$ received BMS. The two groups shared similar clinical and angiographic characteristics. More than $90 \%$ of patients had left ventricular ejection fraction of $\geq 35 \%$. The majority of patients had distal left main disease (81.4\% in DES group and $72.0 \%$ in BMS group). Only a minority of patients $(5.4 \%)$ had isolated left main disease, whereas $72.9 \%$ had left main and at least two-vessel disease. A high rate of IVUS use was observed in the cohort (84.7\%). Final kissing balloon dilatation was performed in $>50 \%$ of the patients and in all patients with two-stent approach. Other adjuvant PCI devices such as rotational atherectomy were rarely required in this cohort. 
TABLE 2. Angiographic and procedural characteristics

\begin{tabular}{|c|c|c|c|c|}
\hline \multirow[t]{2}{*}{ Characteristic } & \multicolumn{3}{|c|}{ No. $(\%)$ of patients or mean \pm standard deviation } & \multirow[t]{2}{*}{ P value } \\
\hline & All patients $(n=111)$ & DES ( $n=86)$ & BMS (n=25) & \\
\hline Intra-aortic balloon pump & $6(5.4)$ & $4(4.7)$ & $2(8.0)$ & 0.615 \\
\hline Glycoprotein IIb/IIla inhibitors & 0 & 0 & 0 & \\
\hline Lesion type & & & & 0.308 \\
\hline Ostial/body & $23(20.7)$ & $16(18.6)$ & $7(28.0)$ & \\
\hline Distal & $88(79.3)$ & $70(81.4)$ & $18(72.0)$ & \\
\hline Two-stent techniques & $39(35.1)$ & $31(36.0)$ & $8(32.0)$ & 0.709 \\
\hline Extent of diseased vessel & & & & 0.137 \\
\hline Left main only & $6(5.4)$ & $3(3.5)$ & $3(12.0)$ & \\
\hline Plus 1-vessel disease & $24(21.6)$ & $16(18.6)$ & $8(32.0)$ & \\
\hline Plus 2-vessel disease & $37(33.3)$ & $31(36.0)$ & $6(24.0)$ & \\
\hline Plus 3-vessel disease & $44(39.6)$ & $36(41.9)$ & $8(32.0)$ & \\
\hline Right coronary artery disease & $63(56.8)$ & $50(58.1)$ & $13(52.0)$ & 0.477 \\
\hline Total No. of stents in left main & $1.3 \pm 0.4$ & 1.3 & 1.2 & 0.089 \\
\hline No. of stents excluding left main & $2.0 \pm 0.7$ & $2.0 \pm 0.7$ & $1.8 \pm 0.7$ & 0.219 \\
\hline Stent size at main branch (mm) & $3.5 \pm 0.4$ & $3.4 \pm 0.4$ & $3.7 \pm 0.6$ & 0.008 \\
\hline Stent size at side branch (mm) & $3.0 \pm 0.4$ & $3.0 \pm 0.5$ & $2.8 \pm 0.3$ & 0.273 \\
\hline Stent length at main branch (mm) & $21.2 \pm 7.9$ & $22.6 \pm 7.5$ & $16.3 \pm 7.4$ & 0.937 \\
\hline Stent length at side branch (mm) & $17.4 \pm 6.0$ & $17.5 \pm 6.0$ & $16.3 \pm 7.5$ & 0.823 \\
\hline Maximum balloon size (mm) & $3.6 \pm 0.6$ & $3.6 \pm 0.4$ & $3.9 \pm 1.0$ & 0.082 \\
\hline IVUS use & $94(84.7)$ & $77(89.5)$ & $17(68.0)$ & 0.008 \\
\hline Post-dilatation & $94(84.7)$ & $75(87.2)$ & $19(76.0)$ & 0.171 \\
\hline Kissing balloon & $65(58.6)$ & $51(59.3)$ & $14(56.0)$ & 0.768 \\
\hline Rotablation & $3(2.7)$ & $3(3.5)$ & 0 & 0.461 \\
\hline
\end{tabular}

Abbreviations: BMS = bare-metal stents; DES = drug-eluting stents; IVUS = intravascular ultrasound

TABLE 3. Incidence of in-hospital major adverse cardiac and cerebrovascular events

\begin{tabular}{lc}
\hline Adverse event & Incidence \\
\hline Death & $1(0.9 \%)$ \\
Non-fatal MI & $3(2.7 \%)$ \\
Stroke & $1(0.9 \%)$ \\
TLR & 0 \\
\hline
\end{tabular}

Abbreviations: $\mathrm{MI}=$ myocardial infarction; TLR = target lesion revascularisation

Of the 86 patients who received DES at the left main segment, 24 (27.9\%) received first-generation DES, 56 (65.1\%) received second-generation DES, and $\operatorname{six}(7.0 \%)$ received both types.

\section{Outcomes}

Procedural success was achieved in 109/111 (98.2\%) cases. There was one death $(0.9 \%)$ and one stroke (0.9\%) but there was no Q-wave MI, stent thrombosis, or urgent repeat revascularisation events during hospitalisation (Table 3).

The mean duration of clinical follow-up was $26.1 \pm 12.6$ months. Table 4 depicts the incidence of adverse outcomes in all patients at the end of followup. There was no significant difference between the
TABLE 4. Cumulative incidence of major adverse cardiac and cerebrovascular events at the end of follow-up

\begin{tabular}{lccc}
\hline & \multicolumn{2}{c}{ No. (\%) of patients } & \multirow{2}{*}{ P value* $^{*}$} \\
\cline { 2 - 3 } & DES (n=86) & BMS (n=25) & \\
\hline Cardiac death & $5(5.8)$ & $4(16.0)$ & 0.191 \\
Non-fatal MI & $3(3.5)$ & $2(8.0)$ & 0.262 \\
Stroke & $2(2.3)$ & 0 & - \\
TLR & $8(9.3)$ & $8(32.0)$ & 0.001 \\
MACCE & $17(19.8)$ & $11(44.0)$ & 0.004 \\
\hline
\end{tabular}

Abbreviations: BMS = bare-metal stents; DES = drug-eluting stents; MACCE = major adverse cardiac and cerebrovascular events; MI = myocardial infarction; TLR = target lesion revascularisation

* P values were calculated by the Kaplan-Meier method and compared by the log-rank test

DES and BMS groups in the cumulative incidences of cardiac death $(5.8 \%$ for DES vs $16.0 \%$ for BMS; $\mathrm{P}=0.191)$ or non-fatal MI $(3.5 \%$ vs $8.0 \% ; \mathrm{P}=0.262)$. Compared with BMS, use of DES was associated with significantly lower risks of TLR $(9.3 \%$ vs $32.0 \%$; $\mathrm{P}=0.001)$ and MACCE (19.8\% vs $44.0 \% ; \mathrm{P}=0.004)$ [Fig]. Target lesion revascularisation was ischaemiadriven in $4 / 16$ (25\%) patients; in the remaining $12 / 16(75 \%)$ patients, TLR was driven by restenosis 


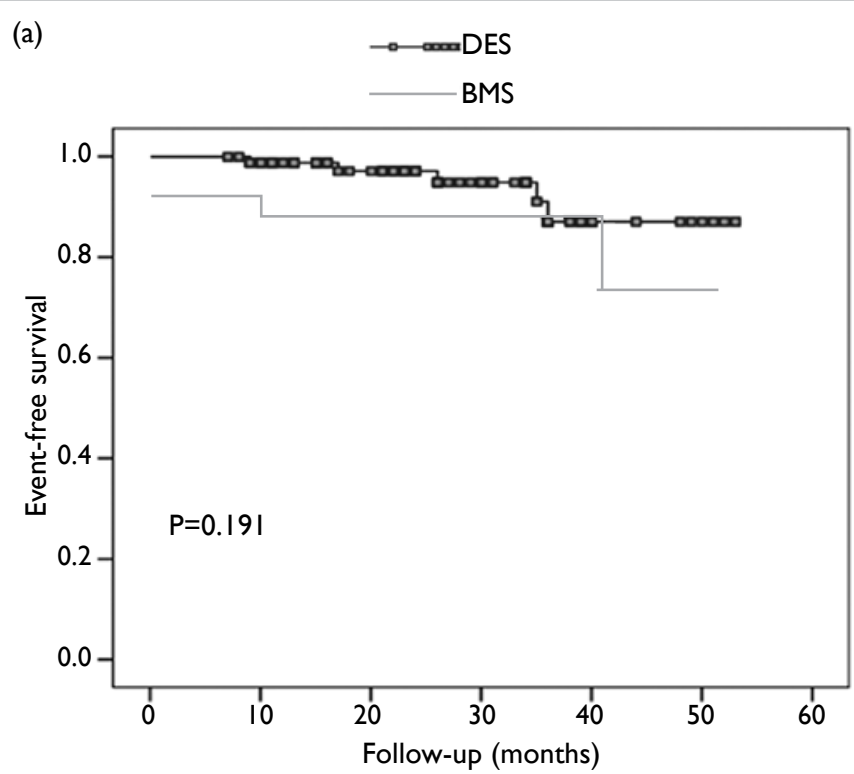

(c)

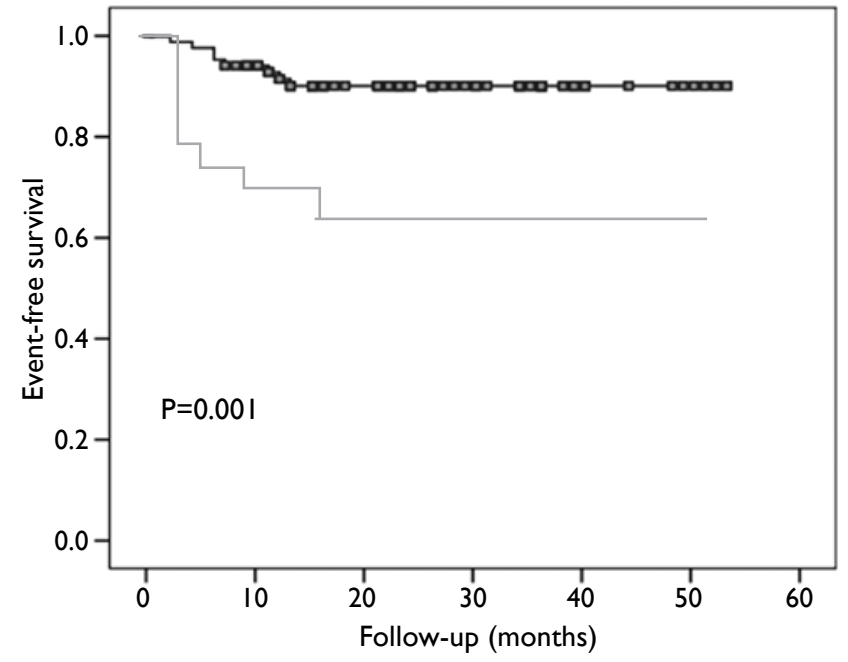

(b)

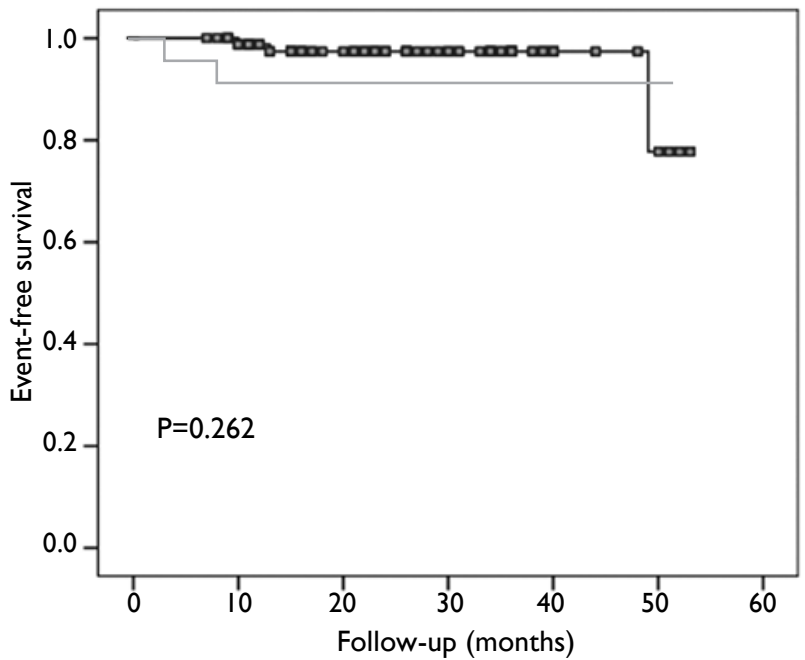

(d)

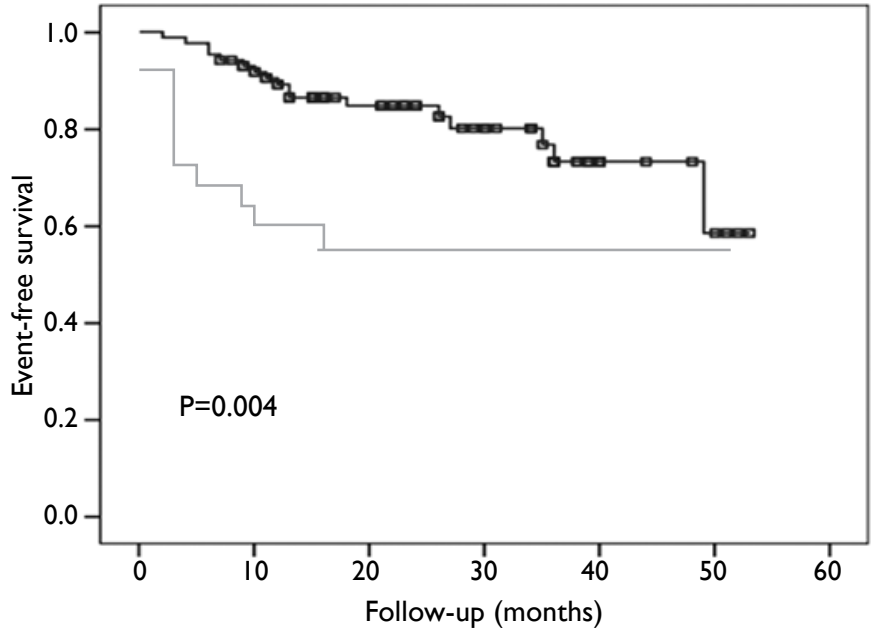

FIG. Kaplan-Meier curves for (a) cardiac death, (b) non-fatal MI, (c) TLR, and (d) MACCE, stratified by DES and BMS respectively (P values are for logrank tests)

Abbreviations: BMS = bare-metal stents; DES = drug-eluting stents; MACCE = major adverse cardiac and cerebrovascular events; $\mathrm{MI}=$ myocardial infarction; TLR = target lesion revascularisation

identified at surveillance angiography after the index procedure. Therefore, the crude rate of ischaemiadriven TLR was only $4 / 111$ (3.6\%) in the overall cohort. The mean timing of TLR was $7.6 \pm 4.3$ months (range, 2-16 months) after the index procedure.

Of 111 cases, $93(83.8 \%)$ underwent routine surveillance angiography 6 to 9 months after PCI; binary restenosis occurred in 22/111 (20\%) cases. Restenosis occurred predominantly in patients with distal left main coronary artery disease $(19 / 22$ [86\%]); and more than half of them $(12 / 22[55 \%])$ had isolated focal restenosis involving the ostium of the left circumflex artery only. Restenosis occurred less frequently with DES than with BMS (12/86 [14.0\%] vs $10 / 25$ [40.0\%]; $\mathrm{P}=0.004)$.
For stent thrombosis, the event rate was extremely low across the whole cohort. One patient receiving BMS implantation developed subacute stent thrombosis after hospital discharge (which resulted in sudden cardiac death). There was no stent thrombosis of any forms in the DES group.

\section{Discussion}

The principal findings of the present study were: (1) performing PCI for ULMCA disease was safe and feasible in selected patients with high procedural success rate (98.2\%); (2) after an intermediate-term follow-up of 26.1 months, the incidence of MACCE in patients receiving DES implantation was similar 
to that reported in recent major international clinical trials including the SYNTAX trial ${ }^{5}$; (3) compared with BMS, the use of DES was associated with a lower risk of restenosis and repeat revascularisation without an increased risk of death or MI.

Historically, CABG has been regarded as the gold standard of treatment for ULMCA disease. Clinical outcomes after PCI for ULMCA stenosis have been shown to vary widely, according to patients' clinical and angiographic features. ${ }^{6,7}$ The high procedural success rate in our study further confirms the technical feasibility of treating ULMCA lesions with the current PCI techniques in the absence of on-site surgical support.

Promising results were reported from randomised trials comparing first-generation DES versus CABG. ${ }^{5,8,9}$ In the SYNTAX trial, ${ }^{5}$ patients were stratified according to the presence of ULMCA disease and randomised to CABG $(n=348)$ or PCI with paclitaxel-eluting stents $(n=357)$. In the ULMCA subgroups, MACCE at 12 months was comparable between patients treated with PCI and $\mathrm{CABG}$. Moreover, although the rate of repeat revascularisation among patients with ULMCA disease was significantly higher in the PCI subgroup, this result was offset by a significantly higher rate of stroke in the CABG subgroup.

The SYNTAX trial ${ }^{5}$ included patients with heterogeneous angiographic characteristics in the left main subgroup (13\% with isolated left main coronary artery disease, $20 \%$ with left main plus single-vessel disease, $31 \%$ with two-vessel disease, and 37\% with triple-vessel disease). Although calculation of the SYNTAX score was not incorporated in routine clinical practice at the time of our study, our cohort demonstrated similar heterogeneity and complexity (Table 2).

We report an intermediate-term outcome (mean follow-up of approximately 26 months) for patients with ULMCA PCI, and our results were comparable with those of the SYNTAX trial. ${ }^{5}$ At 2 years, the SYNTAX trial $^{5}$ reported a MACCE rate of $22.9 \%$ in the left main subgroup (including death from any causes, MI, stroke, or repeat revascularisation), which was comparable with the incidence of $19.8 \%$ reported in our study.

The incidence of TLR in the subgroup of DES in our registry (9.3\%) might be lower than that reported in the SYNTAX trial $^{5}$ at 2 years (any revascularisation, $17.3 \%$ ) and it might be due to inclusion of secondgeneration DES in two thirds of the patients treated with DES in our registry. The higher rate of IVUS use for optimisation (approximately $90 \%$ of cases using DES in our cohort) might also be another reason. One of the main limitations of the SYNTAX trial was thought to be the lack of IVUS use for ULMCA disease in the PCI group. Clinical trials ${ }^{10}$ have shown that patients whose coronary interventions are guided by IVUS have larger post-procedure stent areas and significant reductions in TLR than those undergoing angiography-guided PCI only. Registry data have also shown a trend towards reduced mortality in IVUS-guided ULMCA PCI. ${ }^{11}$

It is worth considering that SYNTAX did not have an 'all-comers' design, where patients with acute coronary syndrome and cardiogenic shock were excluded. Our registry did have an 'all-comers' design, by including patients presenting with stable angina, acute coronary syndrome, ST-elevation and non-ST elevation MI, as well as cardiogenic shock. This might reflect a more 'real-world' situation in daily clinical practice. Despite the inclusion of patients with higher clinical risk, the incidence of events remained low in our study during the index hospital admission and upon medium-term follow-up.

In the BMS subgroup, we reported a high incidence of restenosis (40\%) and TLR (32\%). To date, no randomised controlled trials have been performed using BMS in ULMCA PCI. The longest follow-up available in the literature was from the ASAN-MAIN (ASAN Medical Center-Left MAIN Revascularization) Registry $(n=350$ : BMS, $n=100$; CABG, $n=250),{ }^{12}$ which also reported a high rate of TLR (24.9\%) after long-term follow-up. Although the incidence of restenosis and TLR might be overrepresented due to the use of routine surveillance angiography in our study, the results suggest that the use of BMS was not favoured.

As mentioned, the situation in Hong Kong is unique in that the public health care system does not cover the cost of using DES in ULMCA disease. Patients with financial difficulty can only choose PCI with BMS or CABG. Because of this restraint, the proportion of patients with ULMCA disease in Hong Kong treated with BMS probably exceeds that in other developed countries. In our opinion, a review of this health care policy is necessary.

In our cohort, the rate of cardiac deaths in the BMS group was relatively high $(16.0 \%$ in BMS vs $5.8 \%$ in DES). While this could be a finding by chance, it could be attributed to a multitude of reasons. Compared with the DES group, a higher proportion of patients presented with acute coronary syndrome including cardiogenic shock in the BMS group (Table 1). Moreover, there was a higher proportion of patients with chronic renal failure or prior stroke in the BMS group (Table 1). Such differences might explain the relatively high cardiac mortality rates in the BMS group. Another postulation is that patients who received BMS implantation may have come from a lower socioeconomic class, which might have an impact on their health status and outcome.

The role of routine surveillance angiography remains unclear and controversial. Repeat angiography is suggested because patients with 
left main restenosis are considered to be at high risk for adverse events. However, angiography is unable to predict when a patient might be prone to stent thrombosis, and angiography might be associated with a non-negligible risk in patients who have undergone left main stenting. ${ }^{13}$ Therefore, the 2009 focused update does not recommend routine angiographic follow-up after ULMCA stenting. ${ }^{14}$ Our result is in line with the guideline as the angiographic restenosis rate in the DES group was low. This would have been even lower had a clinically driven approach been used. Given the low event rate in our cohort, we also recommend that routine surveillance angiography is not necessary and patients can be followed up clinically.

An interesting point is that the risk of stent thrombosis was extremely low $(<1 \%)$ given the standard prescription of 1-year dual antiplatelet therapy with aspirin and clopidogrel in this group of high-risk patients with multiple complex stenting. No laboratory or genetic assessment was performed on the degree of platelet function inhibition.

The present study had several limitations. Firstly, it was a single-centre non-randomised retrospective study, which might have significantly affected the results due to unmeasured confounders, procedure bias, or detection bias. Secondly, angiographic results were based on visual angiographic or IVUS assessment and a standardised core laboratory anatomical examination was not performed. Thirdly, incomplete angiographic followup might underestimate the incidence of restenosis. Finally, this study included high-risk patients with complex coronary anatomy who underwent PCI (including patients who refused bypass surgery); these patients were prone to poor clinical outcomes. Therefore, these results might not be generalised to all populations with ULMCA stenosis, especially those with low-to-intermediate SYNTAX score.

\section{Conclusions}

These are the largest available data on ULMCA PCI in Hong Kong. Performing PCI for ULMCA disease was safe and feasible in selected patients with high procedural success. Despite the inclusion of high-risk patients, the incidence of MACCE after intermediate-term follow-up in patients receiving DES implantation was similar to that reported in major clinical trials. Compared with BMS, DES was associated with a reduced need for repeat revascularisation without increasing the risk of death or MI for patients with ULMCA disease. Our result suggest that BMS should not be encouraged due to the high incidence of restenosis and TLR.

\section{Declaration}

The authors report no financial relationships or conflicts of interest regarding the content herein.

\section{Acknowledgements}

The authors wish to thank Dr CY Mui and Dr TK Lau for their assistance in data collection.

\section{References}

1. DeMots H, Rösch J, McAnulty JH, Rahimtoola SH. Left main coronary artery disease. Cardiovasc Clin 1977;8:201-11.

2. Eagle KA, Guyton RA, Davidoff R, et al. ACC/AHA 2004 guideline update for coronary artery bypass graft surgery: a report of the American College of Cardiology/American Heart Association Task Force on Practice Guidelines (Committee to Update the 1999 Guidelines for Coronary Artery Bypass Graft Surgery). Circulation 2004;110:1168-76.

3. LevineGN, Bates ER, BlankenshipJC, etal.2011 ACCF/AHA/ SCAI guideline for percutaneous coronary intervention. A report of the American College of Cardiology Foundation/ American Heart Association Task Force on Practice Guidelines and the Society for Cardiovascular Angiography and Interventions. J Am Coll Cardiol 2011;58:e44-122.

4. Cutlip DE, Windecker S, Mehran R, et al. Clinical end points in coronary stent trials: a case for standardized definitions. Circulation 2007;115:2344-51.

5. Serruys PW, Morice MC, Kappetein AP, et al. Percutaneous coronary intervention versus coronary-artery bypass grafting for severe coronary artery disease. N Engl J Med 2009;360:961-72.

6. Park SJ, Kim YH, Lee BK, et al. Sirolimus-eluting stent implantation for unprotected left main coronary artery stenosis: comparison with bare metal stent implantation. J Am Coll Cardiol 2005;45:351-6.

7. Price MJ, Cristea E, Sawhney N, et al. Serial angiographic follow-up of sirolimus-eluting stents for unprotected left main coronary artery revascularization. J Am Coll Cardiol 2006;47:871-7.

8. Park SJ, Kim YH, Park DW, et al. Randomized trial of stents versus bypass surgery for left main coronary artery disease. N Engl J Med 2011;364:1718-27.

9. Boudriot E, Thiele $\mathrm{H}$, Walther $\mathrm{T}$, et al. Randomized comparison of percutaneous coronary intervention with sirolimus-eluting stents versus coronary artery bypass grafting in unprotected left main stem stenosis. J Am Coll Cardiol 2011;57:538-45.

10. Hong MK, Mintz GS, Lee CW, et al. Intravascular ultrasound predictors of angiographic restenosis after sirolimuseluting stent implantation. Eur Heart J 2006;27:1305-10.

11. Park SJ, Kim YH, Park DW, et al. Impact of intravascular ultrasound guidance on long-term mortality in stenting for unprotected left main coronary artery stenosis. Circ interventions 2009;2:167-77.

12. Park DW, Kim YH, Yun SC, et al. Long-term outcomes after stenting versus coronary artery bypass grafting for unprotected left main coronary artery disease. J Am Coll Cardiol 2010;56:1366-75.

13. Lee MS, Kapoor N, Jamal F, et al. Comparison of coronary artery bypass surgery with percutaneous coronary intervention with drug-eluting stents for unprotected left main coronary artery disease. J Am Coll Cardiol 2006;47:864-70.

14. Kushner FG, Hand M, Smith SC Jr, et al. 2009 focused updates: ACC/AHA guidelines for the management of patients with ST-elevation myocardial infarction (updating the 2004 guideline and 2007 focused update) and ACC/ AHA/SCAI guidelines on percutaneous coronary intervention (updating the 2005 guideline and 2007 focused update). J Am Coll Cardiol 2009;54:2205-41. 